\title{
PEMODELAN FLUKTUASI MUKA AIR TANAH UNTUK MENDUKUNG PENGELOLAAN AIR PADA PERTANIAN LAHAN RAWA PASANG SURUT TIPE A/B
}

\author{
Ngudiantoro (ngudiantoro@yahoo.com) \\ Fakultas MIPA Universitas Sriwijaya, \\ Hidayat Pawitan \\ Fakultas MIPA IPB \\ Muhammad Ardiansyah \\ Fakultas Pertanian IPB \\ M. Yanuar J. Purwanto \\ Fakultas Teknologi Pertanian IPB \\ Robiyanto H. Susanto \\ Fakultas Pertanian Universitas Sriwijaya
}

\begin{abstract}
The objectives of this research are to develop a model of water table fluctuation on tidal lowland area of $A / B$ type. The results of the research are expected to support of the agricultural development on tidal lowland area, especially on water management, because the water management play an important role in the agricultural on tidal lowland area. The water table on tidal lowland area fluctuates according to space and time. The water table controls at a certain depth can support the plant growth and the pyrite oxidation restraint. The model of water table fluctuation which is developed in this research based on the ellipse concept. The research was conducted on the reclamation area of tidal lowland at the fourth tertiary block in P8-12S Delta Telang I, Banyuasin district, South Sumatra province. The simulations of model show good result of estimating the depth of water table on tidal lowland area of A/B type. The proportion of variation the depth of water table which can be explained by model that is $89,6 \%$ up to $95,5 \%$ with standard error of the estimate is 0,021-0,035 meters. The parameter of the water level in the tertiary canals has high sensitivity to the model.
\end{abstract}

Key words : modeling, water management, water table.

Lahan rawa, baik rawa pasang surut maupun rawa non-pasang surut (rawa lebak), merupakan salah satu sumber daya alam yang sangat potensial dan lokasinya tersebar hampir di seluruh wilayah Indonesia. Luas lahan rawa di Indonesia diperkirakan mencapai 33 juta hektar yang terdiri dari 20 juta hektar lahan rawa pasang surut dan 13 juta hektar lahan rawa non-pasang surut. Dari luasan tersebut, total lahan rawa yang telah dikembangkan pemerintah kurang lebih 1,8 juta 
hektar, terdiri dari 1,5 juta hektar lahan rawa pasang surut dan 0,3 juta hektar lahan rawa non-pasang surut (Departemen Pekerjaan Umum, 2007).

Lahan rawa dapat dimanfaatkan untuk pertanian tanaman pangan dan hortikultura, perkebunan, perikanan, hutan tanaman industri, konservasi sumber daya alam, dan ekowisata. Pengembangan lahan rawa pasang surut untuk pertanian tanaman pangan, terutama padi, memiliki prospek yang sangat baik dalam upaya memenuhi kebutuhan pangan nasional. Hal ini disebabkan karena semakin berkurangnya lahan pertanian produktif (irigasi teknis), terutama di Pulau Jawa, akibat alih fungsi lahan untuk permukiman, industri, dan kegiatan non-pertanian lainnya. Melalui pengelolaan lahan dan air yang tepat, produksi padi pada lahan rawa pasang surut dapat ditingkatkan dari 1 kali panen dengan rata-rata 2 ton GKP/ha, menjadi 2 kali panen dengan rata-rata 5,5 ton GKP/ha pada MT I dan 3 ton GKP/ha pada MT II (LWMTL, 2006).

Pertanian lahan rawa pasang surut merupakan pengetahuan yang terus tumbuh dan berkembang. Berbagai pemikiran dan penelitian terus dilakukan dalam upaya meningkatkan produksi dan indeks pertanaman (IP). Pada awal reklamasi, sistem jaringan tata air yang dibangun masih merupakan sistem jaringan terbuka dengan fungsi utama untuk drainase. Pengaturan tata air sepenuhnya masih bergantung pada kondisi alam, sehingga kemampuan pelayanan tata air masih sangat rendah. Pada sistem jaringan terbuka, tipe luapan air pasang menjadi pertimbangan utama dalam penerapan sistem usahatani. Noorsyamsi et al. (1984), Widjaja-Adhi et al. (1992), Euroconsult (1996), dan Nugroho (2004) mengklasifikasikan tipe luapan pada lahan rawa pasang surut berdasarkan kemampuan luapan air pasang.

Dengan dibangunnya infrastruktur pengendali air, maka beberapa pokok persoalan teknis dalam pengembangan pertanian lahan rawa pasang surut mulai dapat dipecahkan. Suryadi (1996) menggunakan kondisi hidrotopografi lahan sebagai pertimbangan awal dalam membuat perencanaan untuk pengelolaan air pada lahan rawa pasang surut. Hidrotopografi lahan merupakan perbandingan relatif antara elevasi permukaan tanah dengan tinggi muka air di sungai atau saluran terdekat. Selanjutnya, Susanto (1998) menggabungkan pertimbangan hidrotopografi lahan dan konsep SEW-30 sebagai sistem evaluasi status air di blok sekunder dan tersier. Sistem yang sama juga dikaji oleh Edrissea et al. (2000) dengan menggunakan konsep SEW-30 dan DRAINMOD. Menurut Susanto (2000), pengendalian muka air tanah di blok tersier merupakan suatu proses kunci yang harus dilakukan dengan tepat melalui pengendalian air di saluran tersier.

Pengelolaan air memiliki peranan penting dalam pengembangan pertanian lahan rawa pasang surut, karena pengelolaan air akan mempengaruhi kondisi muka air tanah di petak lahan. Namun demikian, pengelolaan air masih terkendala oleh kondisi infrastruktur pengendali air yang belum memadai. Selain itu, teknik pengelolaan air yang diterapkan juga masih bergantung pada pengamatan muka air tanah secara langsung di lapangan, yaitu dengan membuat sumur-sumur pengamatan. Meskipun memiliki akurasi yang tinggi, namun pengamatan secara langsung memerlukan waktu, tenaga, dan biaya yang besar, serta terbatas pada titik pengamatan dan jangka waktu pengamatan tertentu. Oleh karena itu, penelitian ini bertujuan untuk membangun model penduga yang dapat memprediksi kedalaman muka air tanah di petak lahan, sehingga kondisi muka air tanah di petak lahan dapat diketahui dengan cepat melalui parameter-parameter model sebagai prediktor. 


\section{METODOLOGI}

Bahan dan alat yang digunakan yaitu pipa paralon diameter 2,5 inchi, bor tanah dengan jenis mata pisau terbuka, meteran, papan duga, tabung pembuang (bailer), stopwatch, GPS, waterpass, penakar curah hujan biasa dan gelas ukur, serta termometer. Model fluktuasi muka air tanah pada lahan rawa pasang surut dibangun melalui tahapan pemodelan: deskripsi model, identifikasi sistem fluktuasi muka air tanah, formulasi model fisik muka air tanah, formulasi model matematika, simulasi model, dan validasi model.

\section{HASIL DAN PEMBAHASAN}

Pemodelan fluktuasi muka air tanah pada lahan rawa pasang surut dilakukan di blok tersier, yaitu pada petak lahan di antara dua saluran tersier seperti yang dapat dilihat pada Gambar 1. Lokasi penelitian berada di daerah reklamasi rawa pasang surut, yaitu di blok tersier 4 P8-12S Delta Telang I, Kabupaten Banyuasin, Provinsi Sumatera Selatan. Berdasarkan kondisi hidrotopografi, lahan di blok sekunder P8-12S termasuk dalam kategori lahan tipe A/B. Lahan tipe A selalu digenangi oleh air pasang, baik pasang besar (terjadi pada musim hujan) maupun pada saat pasang kecil (terjadi pada musim kemarau), sedangkan lahan tipe $B$ hanya dapat digenangi oleh air pasang besar saja.

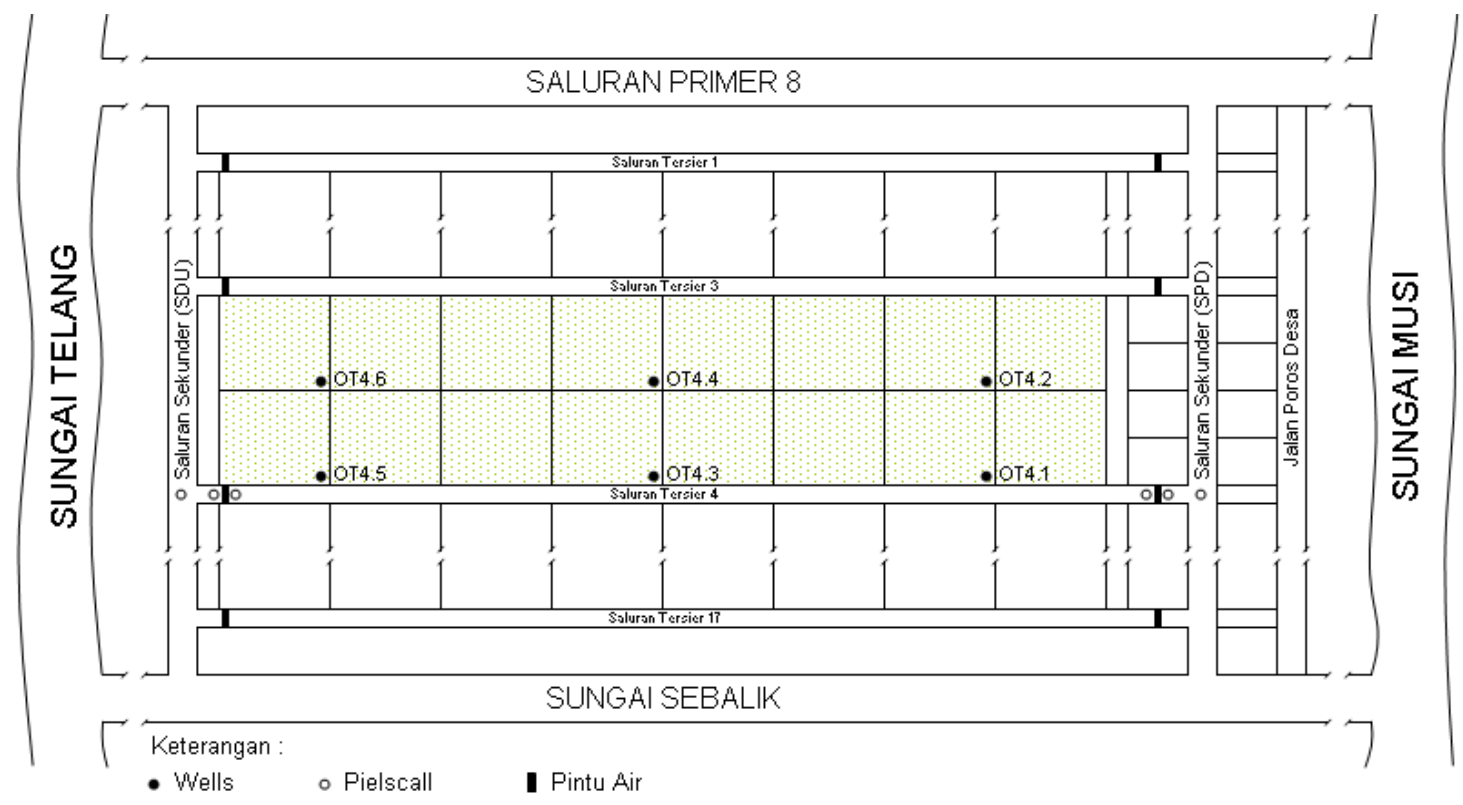

Gambar 1. Sketsa sistem jaringan tata air dan titik pengamatan pada lahan rawa pasang surut tipe A/B di blok tersier 4 P8-12S delta telang I.

Jaringan tata air di daerah reklamasi rawa pasang surut Delta Telang I terdiri dari: 1) Saluran primer, yaitu saluran yang dibuat tegak lurus dan terhubung langsung dengan sungai utama; 2) Saluran sekunder, terdiri dari saluran pengairan desa (SPD) dan saluran drainase utama (SDU), kedua saluran tersebut tegak lurus dan terhubung langsung dengan saluran primer; 3) Saluran tersier, yaitu saluran yang dibuat tegak lurus dan terhubung langsung dengan saluran sekunder; dan 4) Saluran kuarter, yaitu saluran yang dibuat tegak lurus dengan saluran tersier dan terhubung langsung dengan lahan usahatani. 
Lahan usahatani di daerah reklamasi rawa pasang surut Delta Telang I terdiri dari beberapa blok. Tata nama diberikan sesuai dengan hirarki dalam sistem jaringan tata air. Lahan yang berada di antara dua saluran sekunder (SPD dan SDU) disebut sebagai blok sekunder, sedangkan lahan yang berada di antara dua saluran tersier disebut sebagai blok tersier. Dalam satu blok sekunder terdapat 17 saluran tersier, atau terdapat 16 blok tersier. Luas lahan usahatani dalam satu blok tersier yaitu 16 hektar, sehingga total lahan usahatani dalam satu blok sekunder yaitu seluas 256 hektar. Dalam sistem pengelolaan air, untuk setiap blok tersier merupakan satu unit sistem pengelolaan air.

\section{Model Fluktuasi Muka Air Tanah}

Kirkham (1967) dalam van Schilfgaarde (1974) telah merumuskan persamaan tinggi muka air tanah dan jarak antarsaluran yang diilustrasikan melalui bentuk ellips Dupuit-Forchheimer. Selanjutnya, Marino dan Luthin (1982) merumuskan persamaan tinggi muka air tanah dan aliran air dari lahan ke saluran. Persamaan tinggi muka air tanah yang dirumuskan Marino dan Luthin akan sama dengan persamaan Kirkham pada kondisi tinggi muka air di kedua saluran sama.

Pada tahun 1986, Chescheir et al. merumuskan persamaan air rembesan lateral dari dan ke kolom saluran melalui penyelesaian persamaan secara simultan untuk aliran paralel antarsaluran dengan kondisi pembatas mengikuti persamaan Marino dan Luthin. Metode prakiraan untuk mengukur air rembesan lateral dari dan ke kolom saluran yang dikembangkan oleh Chescheir et al. (1986) telah dibandingkan dengan solusi elemen hingga yang berdimensi dua dari persamaan Richard, dan menunjukkan hasil yang sama baiknya. Oleh karena itu, metode prakiraan Chescheir et al. (1986) telah digabungkan ke dalam model pengelolaan air, yaitu model simulasi komputer DRAINMOD yang dikembangkan di North Carolina State University pada pertengahan tahun 1970an.

Model fluktuasi muka air tanah pada lahan rawa pasang surut merupakan modifikasi dari model Kirkham. Pada model ellips yang diilustrasikan oleh Kirkham, dua buah saluran di dalam ellips diletakkan secara bebas, batas tepi saluran tidak ada yang terikat dengan titik-titik utama ellips (titik fokus dan titik puncak ellips).

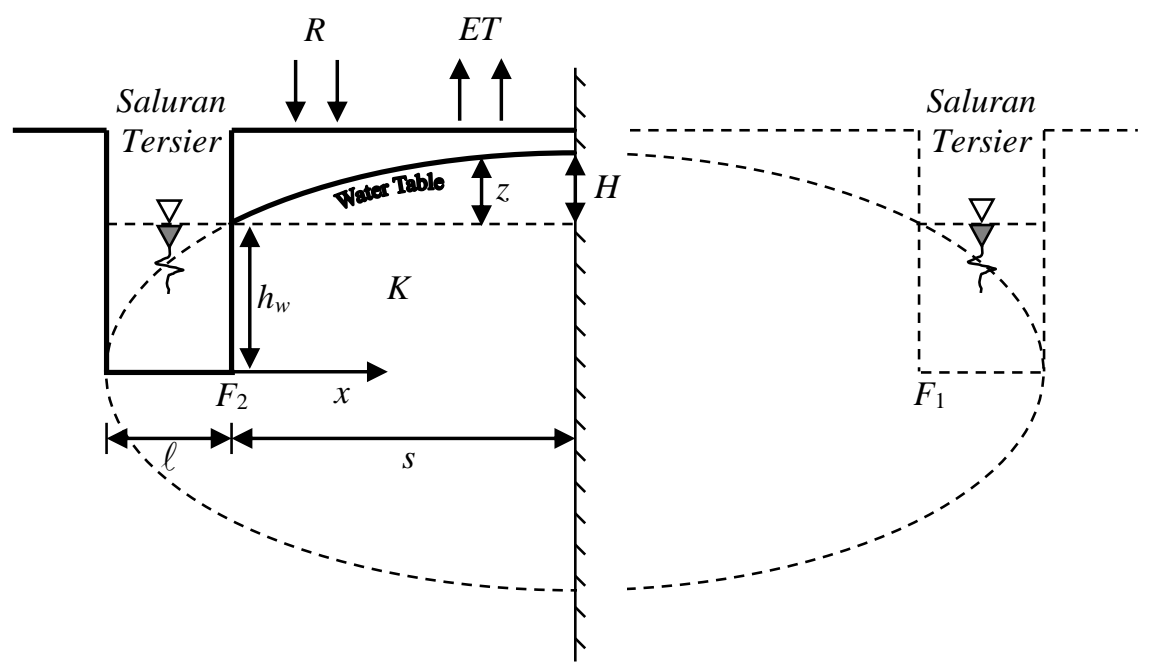

Gambar 2. Modifikasi model ellips Kirkham. 
Berbeda dengan konsep yang dikembangkan oleh Kirkham, model fluktuasi muka air tanah yang dibangun dalam penelitian ini menempatkan batas tepi saluran pada titik-titik utama ellips (Gambar 2), dan didasarkan atas asumsi bahwa:

1. Model ellips untuk muka air tanah mengintroduksi konsep mirror image;

2. Kedalaman saluran sampai pada lapisan kedap; dan

3. Kemiringan permukaan lahan relatif kecil.

Dengan asumsi-asumsi tersebut, maka persamaan ellips pada Gambar 2 dapat ditulis sebagai berikut:

$\frac{(s-x)^{2}}{(s+\ell)^{2}}+\frac{\left(z+h_{w}\right)^{2}}{(s+\ell)^{2}-s^{2}}=1$ dengan $(s+\ell)^{2}-\left(H+h_{w}\right)^{2}=s^{2}$

atau

$h^{2}(x)=h_{w}^{2}+\frac{h_{w}}{s+\ell}\left(2 s x-x^{2}\right)$

Pada kondisi riil, lebar saluran dan jarak antarsaluran adalah tetap, sehingga panjang $s+\ell$ dan $s$ tetap. Tinggi muka air tanah maksimum $\left(H+h_{w}\right)$ dapat berubah karena pengaruh beberapa faktor, antara lain:

1. Peningkatan muka air tanah karena pengisian dari air hujan $(R)$;

2. Penurunan muka air tanah karena proses evapotranspirasi $(E T)$;

3. Pasang surut muka air di saluran tersier $\left(h_{w}\right)$; dan

4. Konduktivitas hidrolik tanah $(K)$, yang mempengaruhi kecepatan aliran air merembes masuk dan keluar lahan.

Jika $H+h_{w}$ berubah, maka $z+h_{w}$ atau $h(x)$ juga akan berubah untuk setiap perubahan pada $x$. Oleh karena itu, apabila parameter input curah hujan $(R)$, evapotranspirasi $(E T)$, dan konduktivitas hidrolik tanah (K) dimasukkan ke dalam Persamaan (2), maka akan diperoleh:

$h^{2}(x)=h_{w}^{2}+\frac{h_{w}}{s+\ell} \frac{R-E T}{K}\left(2 s x-x^{2}\right)$

dengan

$h(x)=$ Tinggi muka air tanah di atas lapisan kedap pada jarak $x$ dari saluran $(\mathrm{m})$.

$h_{w}=$ Tinggi muka air pada saluran di atas lapisan kedap (m).

$R=$ Curah hujan (mm/hari).

$E T=$ Evapotranspirasi ( $\mathrm{mm} /$ hari).

$K=$ Konduktivitas hidrolik tanah (mm/hari).

$x=$ Jarak dari saluran $(\mathrm{m})$.

$2 s=$ Jarak antarsaluran $(\mathrm{m})$.

$\ell=$ Lebar saluran $(\mathrm{m})$.

Selanjutnya, tinggi muka air tanah maksimum terletak pada pusat ellips, dicapai pada saat $x$ $=s$ dan $z=H$, sehingga jarak antarsaluran $(2 s)$ dapat dinyatakan dengan persamaan: 


$$
s=\frac{K}{R-E T} \frac{H_{m}^{2}-h_{w}^{2}}{h_{w}}+h_{w}-\ell
$$

dengan $H_{m}=H+h_{w}$ adalah tinggi muka air tanah maksimum.

Dalam penerapannya, tidak semua sistem jaringan tata air yang dibangun didasarkan atas konsep ellips. Oleh karena itu, pendugaan kedalaman muka air tanah pada lahan tersebut dilakukan dengan menggunakan persamaan:

$$
h^{2}(x)=h_{w}^{2}+\frac{H_{m}}{\sqrt{(s+\ell)^{2}-s^{2}}} \frac{h_{w}}{s+\ell} \frac{R-E T}{K}\left(2 s x-x^{2}\right)
$$

Pada sistem jaringan tata air yang dibangun berdasarkan konsep ellips, $H_{m}=\sqrt{(s+\ell)^{2}-s^{2}}$, sehingga Persamaan (5) akan sama seperti Persamaan (3).

Selanjutnya, tingkat kehandalan model dalam pendugaan ditentukan dari: 1) Nilai koefisien korelasi $(R)$ antara hasil dugaan dan pengamatan; serta 2) Galat baku pendugaan atau root mean square error (RMSE). Kedua nilai tersebut diperoleh dari persamaan berikut:

$$
R=\frac{\sum_{i=1}^{N}\left(x_{i}-\bar{x}\right)\left(y_{i}-\bar{y}\right)}{\sqrt{\sum_{i=1}^{N}\left(x_{i}-\bar{x}\right)^{2} \sum_{i=1}^{N}\left(y_{i}-\bar{y}\right)^{2}}}
$$

dan

$$
R M S E=\sqrt{\frac{\sum_{i=1}^{N}\left(y_{i}-x_{i}\right)^{2}}{N}}
$$

dengan

$$
\begin{aligned}
y_{i} & =\text { Nilai pengamatan pada waktu ke-i. } \\
\bar{y} & =\text { Nilai rata-rata pengamatan. } \\
x_{i} & =\text { Nilai dugaan pada waktu ke-i. } \\
\bar{x} & =\text { Nilai rata-rata dugaan. } \\
N & =\text { Jumlah pengamatan. }
\end{aligned}
$$

\section{Simulasi Model}

Muka air tanah merupakan batas antara zona aerasi dan zona jenuh. Pada zona aerasi, pori tanah berisi udara dan air, sedangkan pada zona jenuh seluruh pori terisi air. Kedalaman muka air tanah pada lahan rawa pasang surut dapat berubah setiap saat, terutama dipengaruhi oleh curah hujan, evapotranspirasi, dan kondisi pasang surut air di saluran. Terjadinya perbedaan antara pengisian dan pengurangan kembali air tanah menyebabkan muka air tanah berfluktuasi.

Grafik pendugaan fluktuasi muka air tanah pada lahan rawa pasang surut tipe $A / B$ di blok tersier 4 P8-12S Delta Telang I dengan menggunakan Persamaan (5) dapat dilihat pada Gambar 3. 


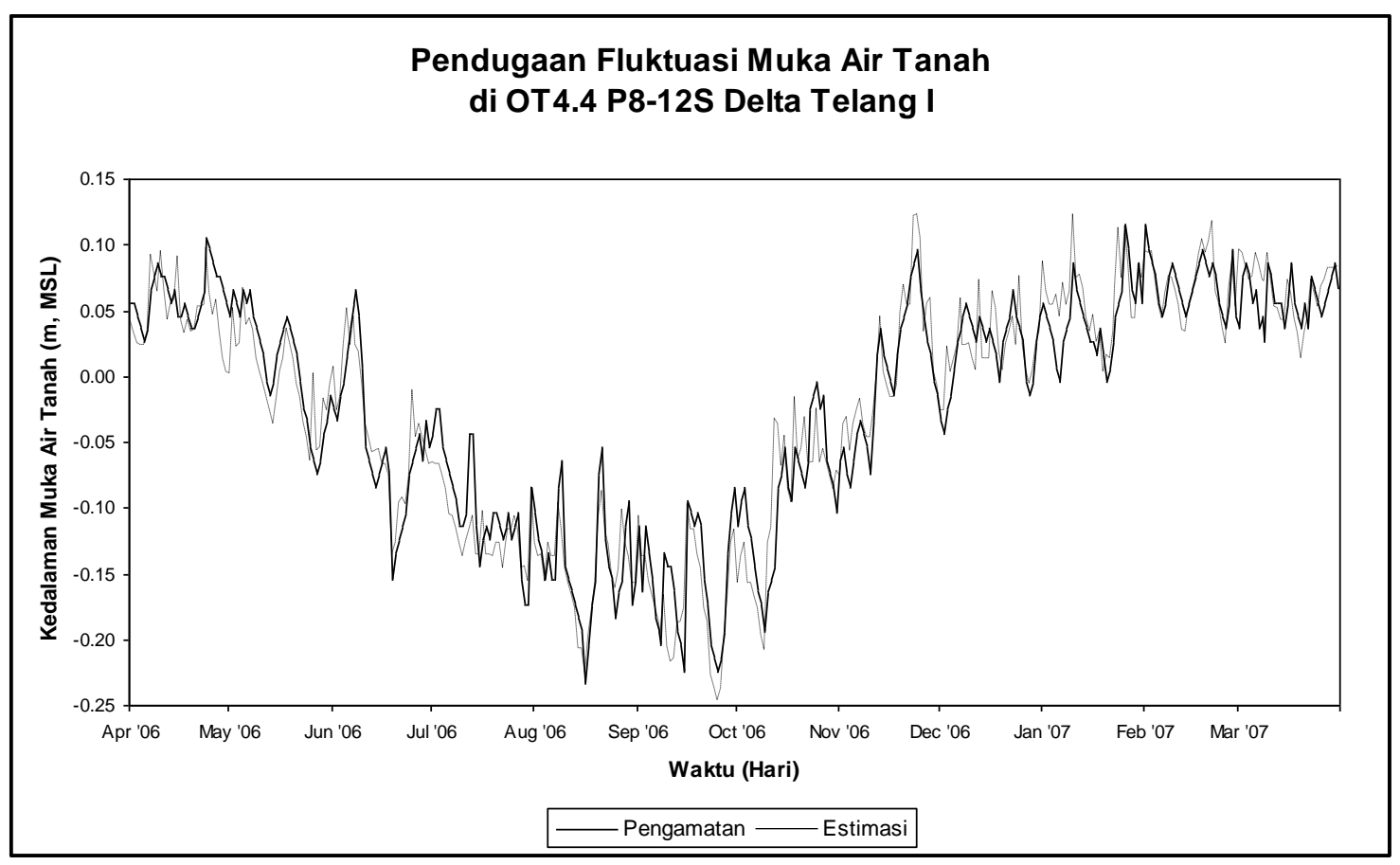

Gambar 3. Pendugaan fluktuasi muka air tanah pada lahan rawa pasang surut tipe A/B di titik pengamatan OT4.4 P8-12S delta telang I.

Dari hasil simulasi yang dilakukan, diketahui bahwa:

1. Model yang dibangun telah dapat memprediksi kedalaman muka air tanah di petak lahan dengan hasil yang baik, ini ditunjukkan dengan nilai koefisien determinasi yang relatif besar dan galat baku pendugaan yang relatif kecil.

Tabel 1. Ringkasan Hasil Pendugaan Kedalaman Muka Air Tanah di Blok Tersier 4 P8-12S Delta Telang I

\begin{tabular}{ccclll}
\hline $\begin{array}{c}\text { Titik } \\
\text { Pengamatan }\end{array}$ & $R$ & $R^{2}$ & \multicolumn{2}{l}{$R M S E$} & \\
\cline { 1 - 4 } OT4.1 & 0,977 & 0,955 & 0,022 & \\
OT4.2 & 0,967 & 0,935 & 0,033 & $R^{2}$ & $=0,928$ \\
OT4.3 & 0,972 & 0,945 & 0,021 & \\
RMSE & $=0,024 \mathrm{~m}$ \\
OT4.4 & 0,963 & 0,928 & 0,024 & \\
OT4.5 & 0,947 & 0,896 & 0,035 & \\
OT4.6 & 0,955 & 0,912 & 0,032 & \\
\hline
\end{tabular}

2. Parameter tinggi muka air di saluran tersier $\left(h_{w}\right)$ memiliki sensitivitas yang tinggi terhadap model. Perubahan muka air di saluran tersier akan menyebabkan perubahan muka air tanah $h(x)$ di petak lahan dengan besaran yang sama. 
3. Parameter curah hujan $(R)$ dan evapotranspirasi $(E T)$ menunjukkan pengaruh yang signifikan terhadap perubahan muka air tanah $h(x)$ pada lahan yang letaknya relatif jauh dari saluran. Namun demikian, pengaruh $R$ dan $E T$ terhadap perubahan $h(x)$ relatif kecil. $R$ dapat meningkatkan $h(x)$ antara $0-5,6 \mathrm{~cm}$, sedangkan $E T$ dapat menurunkan $h(x)$ antara 0-0,6 cm, untuk $0 \leq x \leq 100$ meter.

\section{Pengaturan Tata Air}

Dengan model penduga yang telah dirumuskan, maka kedalaman muka air tanah di lahan usahatani dapat diprediksi, dan kondisi muka air tanah di lahan dapat dikendalikan pada kedalaman tertentu dengan cara mengatur ketinggian muka air di saluran tersier. Agar kondisi muka air tanah dapat mendukung pertumbuhan tanaman, maka kedalaman muka air tanah di petak lahan harus dikendalikan sesuai dengan zona perakaran tanaman. Selain itu, tanaman pada lahan rawa pasang surut akan tumbuh dan berkembang dengan baik apabila pirit yang ada di dalam tanah tidak teroksidasi. Oksidasi pirit dapat dikendalikan dengan menekan kandungan oksigen yang tersedia di dalam tanah, yaitu dengan mengatur kedalaman muka air tanah. Penurunan muka air tanah hingga di bawah lapisan tanah yang mengandung pirit akan menyebabkan terjadinya oksidasi pirit yang menghasilkan senyawa sulfat. Asam sulfat bersifat racun, sehingga dapat mengganggu pertumbuhan tanaman.

Melalui pengelolaan lahan dan air yang tepat, maka produksi dan indeks pertanaman (IP) pada lahan rawa pasang surut akan dapat ditingkatkan. Aspek utama pengelolaan air pada lahan rawa pasang surut yaitu pengendalian muka air tanah yang berfluktuasi sehingga dicapai kondisi muka air tanah di petak lahan yang dapat mendukung pertumbuhan tanaman. Ada tiga hal pokok yang harus diperhatikan dalam pengaturan tata air pada lahan rawa pasang surut tipe $A / B$, yaitu:

1. Retensi air.

Ketika tidak ada hujan dan air di saluran sedang surut, maka muka air tanah di petak lahan akan turun hingga beberapa cm di bawah permukaan tanah. Retensi air dilakukan untuk mempertahankan muka air tanah pada kedalaman tertentu. Penurunan muka air tanah hingga di bawah lapisan tanah yang mengandung pirit dapat menyebabkan terjadinya oksidasi pirit. Selain itu, retensi air juga diperlukan untuk mencegah terjadinya kekurangan air dan menciptakan kondisi lingkungan bagi penyerapan nutrisi yang dibutuhkan tanaman. Retensi air dapat dilakukan dengan cara menutup pintu air di saluran tersier pada saat air surut dan membuka pintu air pada saat pasang. Retensi air sebaiknya tidak dilakukan dalam waktu yang lama untuk mencegah terbentuknya bahan beracun dalam tanah.

2. Drainase.

Drainase dilakukan apabila terjadi kelebihan air pada lahan usahatani, misalnya setelah terjadi hujan lebat. Drainase juga diperlukan pada kondisi-kondisi tertentu seperti sebelum dilakukan pemupukan, pada masa panen, atau ketika kualitas tanah dan air memburuk. Drainase dapat dilakukan dengan cara membuka pintu air di saluran tersier pada saat air surut dan menutup pintu air pada saat pasang. Namun demikian, harus diupayakan agar drainase tidak dilakukan terlalu dalam. Pada areal tertentu, drainase yang terlalu dalam bisa menimbulkan resiko terjadinya oksidasi pirit di bawah permukaan tanah. Oleh karena itu, muka air tanah harus dipertahankan pada kedalaman tertentu agar tetap berada di atas lapisan tanah yang mengandung pirit. 
3. Pemasukan air.

Tanpa irigasi, sumber air utama pada lahan rawa pasang surut berasal dari curah hujan dan air pasang di saluran. Apabila kualitas air layak (tidak asin atau asam), maka pemasukan air ke lahan usahatani dapat dilakukan untuk menjamin kecukupan air bagi tanaman dan juga peningkatan kualitas tanah. Pada kondisi tertentu, genangan air di lahan usahatani perlu dipertahankan untuk berbagai tujuan. Namun demikian, penggenangan lahan dalam waktu yang relatif lama harus dihindari untuk mencegah terbentuknya bahan beracun dalam tanah. Jika selama penggenangan terbentuk unsur racun, maka harus dilakukan pencucian pada saat terjadi hujan atau ketika air di saluran tersier surut.

\section{KESIMPULAN}

1. Model penduga fluktuasi muka air tanah pada lahan rawa pasang surut tipe $A / B$ dan persamaan jarak antarsaluran telah dapat dirumuskan.

2. Proporsi keragaman kedalaman muka air tanah pada lahan rawa pasang surut tipe $A / B$ di blok tersier 4 P8-12S yang dapat dijelaskan oleh model yaitu sebesar $89,6 \%$ hingga $95,5 \%$, dengan galat baku pendugaan 0,021-0,035 meter.

3. Tinggi muka air di saluran tersier merupakan parameter utama dalam pengendalian muka air tanah di petak lahan, sebab perubahan muka air di saluran tersier akan menyebabkan perubahan muka air tanah di petak lahan dengan besaran yang sama, sedangkan curah hujan dan evapotranspirasi hanya memberikan pengaruh yang relatif kecil terhadap kondisi muka air tanah di petak lahan.

\section{UCAPAN TERIMA KASIH}

Penelitian lapangan terlaksana atas dukungan dan bantuan dari banyak pihak. Ucapan terima kasih terutama disampaikan kepada Ditjen Dikti Depdiknas, Dinas PU Pengairan Kabupaten Banyuasin, Dinas PU Pengairan Provinsi Sumatera Selatan, Ditjen Sumber Daya Air Departemen PU, Departemen Pertanian, Universitas Sriwijaya, Pusat Data-Informasi Daerah Rawa dan Pesisir, serta Rijkswaterstaat UNESCO-IHE the Netherlands.

\section{REFERENSI}

Chescheir, G.M., Fipps, G., \& Skaggs, R.W. (1986). An approximate method for quantifying lateral seepage to and from drained fields. Paper; For presentation at the 1986 Winter Meeting American Society of Agricultural Engineers, Hyatt Regency, Chicago IL, December 16-19, 1986.

Edrissea, F., Susanto, R.H., \& Amin, M. (2000). Penggunaan konsep SEW-30 dan DRAINMOD untuk evaluasi status air di petak sekunder dan tersier di daerah reklamasi rawa pasang surut Telang I dan Saleh Sumatera Selatan. Semiloka Manajemen Daerah Rawa dan Kawasan Pesisir. Palembang 4-6 Maret 2000.

Euroconsult. (1996). Buku panduan untuk pengamat proyek telang-saleh. Departemen Pekerjaan Umum, Direktorat Jenderal Pengairan, Direktorat Pembinaan Pelaksanaan Wilayah Barat.

Kirkham, D. (1967). Explanation of paradoxes in dupuit-forchheimer seepage theory. Water Resour. Res. 3;609-622. 
Kirkham, D., Toksöz, S., \& Van Der Ploeg, R.R. (1974).Steady flow to drains and well. in van Schilfgaarde, J. Drainage for Agriculture. Editor. American Society of Agronomy, Inc., Publisher Madison, Wisconsin USA.

LWMTL. (2006). Program manajemen air dan lahan pasang surut (Land and Water Management Tidal Lowlands) di Kabupaten Banyuasin Provinsi Sumatera Selatan. Juni 2004 - Agustus 2006.

Marino, M.A. \& Luthin, J.N. (1982). Seepage and groundwater. Amsterdam: Elsevier Scientific Publishing Co.

Noorsyamsi, H., Anwarhan, H., Soelaiman, S., \& Beachell, H.M. (1984). Rice cultivation in the tidal swamp in Kalimantan. Workshop on research priorities in the tidal swamps rice. IRRI Los Banos Philipine.

Nugroho, K. (2004). Aspek hidrologi dalam klasifikasi tipe luapan pasang surut, studi kasus daerah telang Sumatera Selatan. [Disertasi]. Sekolah Pascasarjana Institut Pertanian Bogor. Bogor.

Suryadi, F.X. (1996). Soil and water management strategies for tidal lowlands in Indonesia. [Disertasi]. A.A. Balkema, Roterdam.

Susanto, R.H. (2000). Manajemen air daerah reklamasi rawa dalam kompleksitas sistem usahatani. Workshop Teknologi Pengembangan Lahan Rawa; Integrated Swamps Development Project Loan. Palembang 29 Agustus-1 September 2000.

Susanto, R.H. (1998). Water status evaluation in tertiary and secondary blocks of South Sumatra reclaimed tidal lowlands using the hidrotopography and SEW-30 concepts. Proceeding of the Young Professional Forum-International Commision on Irrigation and Drainage Seminar (B3). Bali July 23, 1998.

Widjaja-Adhi, I.P.G., Nugroho, K., Suriakarta, D.A., \& Karama, A.S. (1992). Sumber daya lahan pasang surut, rawa dan pantai: Potensi, keterbatasan dan pemanfaatannya. Makalah Utama, Disajikan dalam Pertemuan Nasional Pengembangan Pertanian Lahan Pasang Surut dan Rawa. Bogor, 3-4 Maret 1992. 